\title{
Vaenulike kaksikute positsioon etteantud teogoonilises struktuuris
}

Emily Lyle

Võrdlevas mütoloogias tuleb arvestada kahe paralleelse kaksikutepaariga, nagu Donald Ward teeb kindlaks oma uurimuses Jumalikud kaksikud: indo-euroopa mü̈̈t germaani traditsioonis (1968). Ta ei tegele vaenulike kaksikutega, vaid teise paariga - veedades esinevate Ashvini ${ }^{1}$ kaksikutega. Sellised on kreeka Dioskuurid Kastor ja Polydeukes ${ }^{2}$ kes rooma traditsioonis ilmuvad Castori ja Polluxina. Ashvini kaksikuid käsitletakse tihti lihtsalt paarina ja G. Dumezil pidas neid mõlemaid oma kolmanda funktsiooni (viljakus ja õitseng) kehastuseks. Neil on siiski eristavaid omadusi, mistõttu Douglas Frame määratles neid terminitega "sõjard-hobusemees" ja "intelligentne karjakasvataja". D. Ward vaatles Ashvini kaksikute teemat, lähtudes G. Dumezili kolme funktsiooni - sakraalsus, füüsiline jõud ja viljakus käsitlusest (1968: 20-24) jajõudis järeldusele, et üksnes "karjakasvatajakaksik" esindab kolmandat funktsiooni ja "hobusemees-kaksik" peaks olema seotud teise funktsiooniga (füüsiline jõud). Nõustun, et see on tõenäoline ja lähtun sellest edasises artiklis, kui puudutan Ashvini kaksikute asukohta esitatud panteonis, ent mind huvitab siin peamiselt teine paar - vaenulikud kaksikud. D. Ward on üsna kindel, et nad on Ashvini kaksikuist erinev paar, kuid viitab neile lühidalt (1968: 6-7):

Kaksikud on tihti teineteise vastu väga vaenulikud. On olemas isegi laialt levinud uskumus, et kaksikud võitlevad juba üsas. Sellise vaenulikkuse kuulsaim näide on kaksikupaar Eesav ja Jaakob Piiblis (1. Moos. 25:22). Paralleelne näide on ka Vanas Kreekas Akrisiose ja Proitose näol (Apollodoros, Bibl. II: 2,1). Asjaolu, et jumalikud kaksikud esindavad vastandlikke iseloome, võib toetada ka mütoloogilises traditsioonis nendevahelist vaenulikkust. See teema on üleüldiselt levinud ja tuntud ka muude indo-euroopa keeli kõnelevate rahvaste seas (nt Romulus ja Remus). 
Rooma pakub tuntud näited kahe paari kaksikute kohta: Ashvini kaksikuile vastavad Castor ja Pollux (kellest Castor on "hobusemees") ja vaenulikele kaksikuile Romulus ja Remus. G. Dumezil, kes oma süsteemis ei erista vaenulikke kaksikuid ja samastab nad teise paariga, käsitleb mõnikord ka Romulust ja Remust Ashvini kaksikuina (Dumezil 1970: 252-255; Dumezil 1977: 182). Minu meelest on nad aga igal juhul selgeks näiteks vaenulike kaksikute kohta kuni nende vaenu läteteni välja, mida ma määratlen küsimusena, kumb kaksikuist on teisest üle. Kaksikud, olles veel üsas, võivad "tülitseda selle üle, kumb peaks esimesena sündima" (Leach \& Fried 1950: 1135), kuid see on mõtteviisi, et esmasündinu on ka ülem, sekundaarne avaldus. Tüli põhjapanevaks motiiviks on küsimus, kumb kaksikuist jääb domineerima; ja kuigi tüli võtab üsasisese kakluse vormi, võib ta ka omandada muid avaldumisviise. Tähtis on tähele panna, et vaenulike kaksikute võitlus käib kuningavõimu pärast.

See tuleb üsna selgelt ilmsiks D. Wardi mainitud näidete põhjal. Akrisios ja Proitos olid Argose kuninga Lynkeuse ja ta naise Aglaia kaksikpojad ning Apollodoros (Library (Bibliotheke) 2.2.1) ${ }^{3}$ ütleb nende kohta:

Need kaks tülitsesid omavahel, kui olid veel üsas ja kui suureks kasvasid, pidasid sõda linna pärast.

Täiskasvanud meeste antagonismi põhjustab küsimus, kumb on valitseja ja paralleelseis lugudes nähtub, et see on ka üsas tülitsemise põhjuseks. Piibliloos, kui Iisaki naine Rebeka oli rase Jaakobi ja Eesaviga, "lapsed heitlesid tema sees" ning seda seletati talle (1. Moos. 23:25):

Su ihus on kaks rahvast, kaks erinevat hõimu su üsast alates: üks rahvas on vägevam teisest - vanem orjab nooremat. ${ }^{4}$

Sama lugu on terviklikumalt taasesitatud juudi legendis (Ginzberg 1909-1938: 1.313-1.317). Ginzberg märgib, et Eesav vigastas Rebekat tema üska rebides. Jaakob oli esimesena eostatud ja "oleks pidanud sündima esimesena, kuid Eesav ähvardas, et kui Jaakob ei anna talle eesõigust, tapab ta nende ema" (5.271 märkus $16 ; 5.273$ märkus 22). Selles situatsioonis on teatav kahetähenduslikkus. Jaakob oleks pidanud esimesena sündima, aga tegelikult sündis Eesav esimesena. Selle loo endastmõistetavaks kontseptsiooniks on esimese poja eesõigus valitseda. Paradoksaalselt aga peab va- 
nem teenima nooremat, kuna teisena sündinu oli see, kes eostati esimesena, ja on tegelikult esimene poeg.

Esmasündimise teemat ja õigust võimule käsitletakse väga selgesõnaliselt teises vaenulike kaksikute versioonis - zervanistlikus müüdis valgusejumal Ohrmazdi ja pimedusejumal Ahrimani sünni kohta androgüünsest Zurvanist, ${ }^{5}$ kelle nimi tähendab aega ${ }^{6}$ Zurvan lubas, et esmasündinu tema kahest pojast saab kuningaks. Üks jutustus ütleb otsesõnu, et Ohrmazd oli kõigepealt sünnijärjekorras (Zaehner 1955: 66, 433) ja oleks loomulikult sündinud esimesena. Isegi kui seda ära ei märgita, on ikkagi selge, et Zurvan nägi ette Ohrmazdi esmasündi. Ahriman, kuuldes Zurvani lubadusest, torkas üsa läbi ja esitles ennast musta ja haisvana jahmunud Zurvanile ning nõudis kuningavõimu. Olles lubadusega seotud, andis Zurvan Ahrimanile õiguse valitseda esimesena piiratud aja, pärast mida hakkab valitsema Ohrmazd (Zaehner 1955: 68-69, 424-427).

See iraani variant on varjamatult jumalate sündimise lugu, kuid pole oodata, et roomlased, kes eelistasid jutustada müüti kui ajalugu, jumalaist kaksikute müüti otseselt väljendaksid. Nende jutustus vaidlusest kuningavõimu saavutamise üle toimub kohas, kus asub Rooma, ning leiab aset Romuluse ja Remuse vahel, kui nad teevad ettepaneku asutada linn. Liviuse ${ }^{7}(1.6 .4-1.7 .3)$ järgi käis lugu nii:

Kuna nad olid kaksikud ja vanuse järgi lugupidamises vahet teha ei saanud, siis otsustati, et jumalad, selle koha kaitsevaimud, ennustavad lindude järgi, kes annab uuele linnale nime ja valitseb asutatud riiki. Romulus valis auspiitside kohaks Palatinuse künka, Remus Avitinuse. Rä̈̈gitakse, et esimesena tuli Remusele kuus kotkast; just teatati endest Romulusele, kui talle tuli kaks nähtavale sellest kaks korda suurem arv ja mõlemat tervitas tema rahvas kuningana: ühed taotlesid võimu ajalise ennetamise, teised lindude arvu tõttu. ${ }^{8}$

Siin on jälle kahetähenduslikkus ja taas on kuningal, kes saab kestva võimu (Romulus), suurem õigus seda nõuda, kuid esimene taotlus tuleb teiselt vennalt (Remus). Remuse tapab peatselt pärast seda Romulus või ühk ta järgija. On huvitav lugeda Jaan Puhveli (1975) ja Bruce Lincolni (1975) töödes oletuse, et Remus on India surmajumala Jama ${ }^{9}$ vaste. Vaenulike kaksikute narratiivi uurimine laseb teha sama järeldusele. Kontrast kaksikute vahel, mis on eriti ilmekas Iraani traditsioonis, on ühelt poolt kontrast 
valguse ja elu ning teiselt poolt pimeduse ja surma vahel. Jama ('kaksik') ohverdas tema vend Manu ${ }^{10}$ ('mees'), kes on "esimese kuninga" võrdkuju, ja pärast seda sai Jama surnute kuningaks. Remuse tappis Rooma asutaja ja esimene kuningas, tema kaksikvend Romulus (või keegi tema poolel olija) pärast seda, kui ta võitles õiguse eest saada kuningaks. Mõlemal vaenulikest kaksikutest on taotlus omandada kuningavõim ja arvatavasti on müütide ülesehituses oluline element seegi, et mõlemad erinevatel aegadel või erinevates sfäärides päriselt ka valitsevad. See element ei esine Remuse puhul ladina juttudes Rooma asutamise kohta, aga seda leiab kreekakeelses Johannes Malalase ${ }^{11}$ Bütsantsi kroonikas, mis kirjutati 6. sajandil pKr, kuid mis toetus varasemaile allikatele (Cameron 1976: 64-66). Malalas näitab Remust valitsemas koos oma vennaga (siin antud kreekakeelne variant tema nimest: Pø $\mu$ ow (Romos)) nii enne kui pärast oma surma:

Ja pärast seda, kui Rooma asutaja Romos oli kuningas ja tema vend Remos. [---] Mistõttu vendadel tekkis viha teineteise vastu kuningaks olles; ja Romos tappis Remose ja Romos valitses üksinda.

Pärast venna tapmist raputasid kogu Rooma linna maavärinad ja tema valitsemise ajal leidsid aset kodusõjad. Ja Romos läks oraakli juurde ja küsis: "Miks juhtuvad sellised asjad ainult minu kuningavõimu ajal?” Ja pü̈̈tia ${ }^{12}$ ütles talle: "Kui su vend ei istu koos sinuga kuninglikul troonil, vappub sinu linn Rooma ja inimesed ega sõjad ei leebu.” Ja lasknud teha venna pildi järgi tema näo kujutise, see tähendab kuldse portree-büsti tema keha järgi, pani ta selle kuju oma troonile, kus ta istus. Ja niimoodi valitses ta sellest ajast peale koos oma venna Remose kullast kujuga, kes tema kõrval istus. Ja linna värisemine lakkas ning rahva vaen vaibus. Ja ükskõik millist käsku ta seadusi kehtestades $k a$ andis, väljendus ta nagu enda eest ja oma venna eest, öeldes: "Meie käskisime ja otsustasime." 13

Vaenulike kaksikute loo tunnusjooneks on vaidlus selle üle, kummast saab valitseja, s.t nad on kuninglikud kaksikud ning kuningavõim on nende identifitseerimisel sama oluline asjaolu kui nende vaenulikkuse fakt. Malalas kujutab küll viimaks kahte venda sõbralikult koos valitsemas, kuid tuleb tähele panna, et vendade vahel säilib kontrast nende seotuse tõttu ühelt poolt elavatega, teisalt 
surnutega. Kuningate kaksikvendlus ei ole välja toodud loo igas versioonis, kuid need kaks kujundit on äratuntavad isegi juhul, kui neid on käsitletud lihtsalt vendadena, üks neist on valguse ja/ või elu kuningas ja teine pimeduse ja/või surma kuningas. Iraani traditsioonis on nad valguse kuningas Ohrmazd ja pimeduse kuningas Ahriman. Kreekas on aga jumalate valitseja Zeus ja tema vend Hades, kes on pimeduse ja surnute kuningas. India traditsioonis on Manu ja Jama, elavate kuningat käsitletakse "esimese kuningana", samas tema vend on jumal ja surnute kuningas. Samuti Rooma traditsioonis - Romulus elab rahva seas ja valitseb kuningana, kui Remuse valitsemine pärast tema surma saab olla ainult viirastuslikku laadi. Egiptuse müütides ilmuvad vaenulikud kaksikud Sethi, ${ }^{14}$ kes "ei sündinud õigel ajal ega kohas, vaid purustas löögiga ema ja kargas tema ema külje seest välja" (Plutarchos ${ }^{15}$ Isisest ja Osirisest, 12), ja Horosena, ${ }^{16}$ keda samastati elava kuningaga - vaaraoga.

Nüüd võib pöörduda teogoonia poole ja vaadelda kuninga ja temale vastanduva venna positsiooni seal. Kuigi mõningaid kõige huvitavamaid aspekte teogoonia kohta võib leida lugudest, mis on pagendatud eruditsiooni kõrvalteedele, on väärtuslik panus Hesiodose $^{17}$ "Theogonial", mis on üks maailma tuntumaist loomislugudest. Meid ei huvita siin praegu ema Maa mitmekesine järelpõlv. Kuninga kujund muutub kesksemaks, kui me tegeleme jumalate valitseja Zeusi ning tema esivanemate ja õdede-vendadega. Esimene väga ilmne asjaolu, mida tuleb ära märkida, on fakt, et tal on esivanemad. Kuningas ei ole loomisprotsessi alguses, vaid haripunktis. Esimene olend, kellest kõik asjad lähtuvad, on Ge, Maa jumalannana. Tema sünnitab Uranose, Taeva kui jumala, ja pärast vahekorda Uranosega sünnib neile poeg Chronos, kes hiljem tõukab troonilt oma isa. Chronos võtab naiseks Uranose ja Ge tütre Rhea, kes sünnitab talle kolm tütart ja kaks poega, Chronos neelab nad kõik alla. Lõpuks sünnitab Rhea Zeusi, kes päästetakse kavalusega oma isa käest ja elab, kuni saab temast võitu ning sunnib Chronost oma õdesid ja vendi välja oksendama (Hesiodos, Theogonia, 116-187, 453-500; Apollodoros, Bibliotheke, 1.1.1-1.2.1). Joonis 1 näitab neid sugulussidemeid. Ge esineb nii algallikana kui ka naispoolena esimesel paaritumisel. Vanad jumalad, Zeusi esivanemad, on eraldatud punktiirjoonega Zeusist ja tema õededestvendadest, kes on üles loetletud sündimise järjekorras. 
Algallikas

Ge (n)

Vanem

jumalate

Uranos (m)

Ge (n)

põlvkond

Chronos (m)

Rhea (n)

Noorem

jumalate

Hestia (n) Demeter (n) Hera (n)

põlvkond

Hades (m) Poseidon (m) Zeus (m)

Joonis 1.

Joonisel on märgatav sümmeetria ja ma juhin tähelepanu eriti vanemate jumalate tavapärasele või nn Noa laeva mudelile - iga meesjumal oma jumalannaga. Oletan, et antud juhul on varasem asümmeetriline mudel kohandatud sümmeetrilisesse vormi. Sümmeetrilise "laeva" mudeli võib leida ka egiptuse traditsioonis Heliopolise enneaadis ${ }^{18}$ mille kohta Henri Frankfort annab järgmise kirjelduse (1948: 182).

Kaugel sellest, et tegu on juhusliku jumaluste kombinatsiooniga, keda juhtuti linnas austama, vaid see rühmitus esindab üht religioosselt väga tähtsat kontseptsiooni.

Tema tipus asus looja-päike Atum, ${ }^{19}$ siis järgnes jumalik paar, kelle lõi Atum iseendast-Shu ja Tefnut, õhk ja niiskus. Järgnesid selle paari lapse olid Geb ja Nut ${ }^{20}$ - maa ja taevas. Nende lapsed Osiris ja Isis ning Seth ja Nephthys on Enneaadi viimased neli jumalat.

Viimase nelja ja neile eelneva viie jumala vahel on selge erinevus. Atum, Shu ja Tefnut ning Geb ja Nut esindavad kosmoloogiat. Nende nimed kirjeldavad algelemente, nendevahelised suhted viitavad loomisloole. Gebi ja Nuti neli last aga ei ole segatud universumi kirjeldusse.

Frankfort lisab veel: "Kuigi Horos elava kuningana asus väljaspool Enneaadi, seisis ta siiski selle teoloogilise konstruktsiooni keskpunktis" ja "teda kutsutakse mõnikord 'kümnendaks jumalaks'." 21 Kaasates ka kuningas Horose, on siinses jadas kümme jumalat, esimene osa koosneb "viiest kosmilisest jumalast", nagu Frankfort (1948: 183) neid nimetab, ja teine osa noortest jumalatest. Joonis 2 näitab seda jaotust ja eristab ka Atumi kui algallika teistest kosmilistest jumalatest: 
Algallikas

$\operatorname{Atum}(\mathrm{m})$

\begin{tabular}{lcc}
\hline Vanemad & \multicolumn{1}{c}{ Shu $(\mathrm{m})$} & Geb $(\mathrm{m})$ \\
jumalad & Tefnut (n) & Nut (n) \\
\hline Nooremad & & \\
jumalad Osiris (m) Horos (m) Seth (m) & Isis (n) Nephthys (n)
\end{tabular}

Joonis 2.

Horos oli kuningas, kuid tema troonitaotluse vaidlustas ta vend Seth, kes nõudis kuningavõimu kohtu abil, ning esimese otsuse järgi määrati talle pool kuningriiki (Griffiths 1960: 65-74; te Velde 1967: 59-64). See otsus muudeti hiljem ära, kuid isegi siis, kui Horosele oli antud terve kuningriik, tunnistati asjaolu, et Sethil oli teatud õigus, kombineerides tema sümboleid Horose omadega.

Kolmandast sajandist eKr pärinevates püramiiditekstides on viide "jumalate sünnile viiel juurdepandud päeval" (Mercer 1952: $1.292,3.883)$ ja kalendrid näitavad, et nende viie päevaga seotud jumalad on Osiris, Horos, Seth, Isis ja Nephthys. ${ }^{22}$ Niisiis ilmneb, et neid viit jumalust saab vaadelda varase perioodi õdede ja vendade rühmana, kes sündisid järjestikku, kuid nii lähestikku koos, et nad on mitmiksünni motiivi näiteks. Mitmiksünnile eelnenud eostamisloo jutustajaks on ainult Plutarchos esimesest sajandist $\mathrm{pKr}$ kirjutises "Isisest ja Osirisest", kuid tema kirjeldus esitab vanade jumalate asümmeetrilise struktuuri, mis mu meelest kuulub müüdi algseimale tasandile. Plutarchos kasutab kreeka jumalate nimesid egiptuse jumalate vastetena; Chronos näib olevat Gebi vasteks, Helios $^{23}$ Atumi või Re, Hermes ${ }^{24}$ Thothi ja Rhea ${ }^{25}$ Nuti (Griffiths 1970: 291-294), kuid nimede asemel on oluline hoopis müüdi ülesehitus. Heliose roll on siin sarnane Chronose omale Hesiodose "Theogonias", kus too sihilikult sööb ära oma lapsed, takistamaks ettekuulutuse täideminemist, mis ennustab, et ta kukutab kohalt üks poegadest, kes on temast võimsam, ja teda petetakse, asendades tillukese Zeusi kiviga, mille Chronos tema asemel alla neelab. Antud juhul on "tõkestajaks" Helios, kelle tegutsemine oleks ära hoidnud Horose ja teiste noorte jumalate sündimise, kui Hermes ei oleks teda ninapidi vedanud.

Rä̈̈gitakse, et kui Rhea oli Chronosega salaja vahekorras, sai Helios sellest teada ja saatis Rhea peale needuse, mille tõttu ta ei tohtinud ühelgi kuul ega aastal sünnitada. Aga Hermes armus Rheasse ning sai temaga lähedaseks ning 
siis mängis Kuuga kabet. Hermes võitis endale ühe seitsmekümnendiku igast kuu ilmumisest ja pani oma võitudest kokku viis tervet päeva ning lisas need kolmesaja kuuekümnele. Neid viit päeva kutsuvad egiptlased nü̈̈d juurdepandud (epagomenaalseteks) päevadeks ja tähistavad neil jumalate sünnipäevi (Isisest ja Osirisest 12, tõlkinud Griffiths).

Plutarchos lisab: "Nad räägivad, et Osiris ja Aroueris (Horos) olid Heliose järglased, Isis Hermese järeltulija ja Typhon (Seth) ning Nephthys Chronose lapsed." Griffiths kirjutab kommentaariks (1970: 291): "Plutarchose jutustuses Rhea kohta on problemaatiline asjaolu, et tal näib olevat kolm abikaasat." See probleemne iseärasus viitab mu meelest, et Plutarchose lugu on müüdi algvariant, mis ei ole taandatud Hesiodose "Theogonias" ja Heliopolise Enneaadis ilmnevale sümmeetrilisele Noa laeva struktuurile, vaid kirjeldab üht jumalannat paari panduna kolme meesjumalusega.

Isise ja Osirise narratiivile lähim paralleel ei ole legend jumalate kohta, vaid seda räägitakse inimesist tegelaste kohta iiri loos Punaste Triipude Luigaidist. Kuigi on muidugi üldiselt teada, et müütiline materjal võib olla üle kantud inimlikule tasandile, ei olnud konkreetselt seda lugu seni käsitletud kosmogoonilise müüdina, kuni ma teda ühes eelmises artiklis lühidalt puudutasin (Lyle 1982). Lugaidi lugu on aga viljakalt uurinud G. Dumezil (1973), kes tõi välja paralleelse india loo Madhavi ${ }^{26}$ nelja poja eostamisest, mille kohta ma arvan, et see põhineb samuti kosmogoonilisel müüdil. Need kaks lugu esitavad kaks erinevat meetodit, mil viisil on teogoonias loodud viimane põlvkond. Üks variant on, et vanu jumalaid paljundavad nende lapsed, sel juhul sarnaneb noor jumal ühele vanematest; teine võimalus on vanadelt jumalailt pärinevate omaduste kombineerimine, kus noorel jumalal on osaline sarnasus kõigi kolme isaga.

Paljundamine on ilmne india loos. Madhavi magab järjekorras nelja mehega, kellest igaühel on mingi eriline voorus, ja sünnitab järjest neli poega, kellest igaüks pärib oma isa erilise vooruse. G. Dumezil ja van Buitenen (vt Lyle 1982: 36-37) tegid kindlaks, et kolm erinevat voorust on seotud kolme järjestikuse funktsiooniga: 1. rituaalne täpsus, 2 . vaprus, 3 . suuremeelsus ja mina olen tähendanud, et ka 4. - voorus, tõde, mis siin küll on antud osaks isale ja pojale, ent kuulub õigupoolest naisele. Nelja vana jumala kolme meessoost ja ühe naissoost - paljundamine annab neli vastavuses olevat noort jumalat - kolm poega ja ühe tütre. Kogu teogoonia tipnemist sellise paljundamise kaudu võib niisiis näha 
järgmise jadana: 1 (jumalanna) $>2$ (jumalanna pluss esimene jumal) $>4$ (jumalanna, esimene jumal pluss nende kaks poega) $>8$ (jumalanna ja kolm jumalat pluss tütar ja kolm poega).

See jada ei seleta aga teist ülalmainitud loomismeetodit, kombineerimist, mille tulemusel sünnib kuningas, nagu seda näitab Lugaidi-loo uurimine. Nagu G. Dumezil viitas, on Punaste Triipude Lugaidil kõigile kolmele funktsioonile sobivad tunnusjooned ja ta on kolmefunktsionaalne kuningakuju. Ta eostatakse ööl, kui Clothru magab oma kolme venna Nari, Bresi ja Lothariga ja kui Lugaid sünnib, on tal punased joone ümber kaela ja piha, mis märgistavad oma kõigilt kolmelt isalt päritud osasid - ta pea on Nari pea moodi, ta keha ülalpool pihta Bresi ja pihast allpool Lothariga sarnane. Kummaliselt loodud, kuid siiski inimesest Lugaid arvatakse vastavat jumalikule Lugile. Neis eostamislugudes ei ilmu välja kuninga kaksik, kuid küsimus kaksikute põlvnemise kohta on käesolevas kontekstis vähemtähtis seik kui müüdi ülesehitus, kus kaks noort kuningat moodustavad ainulaadse paari ja minu hüpoteesi järgi igaüks noortest jumalatest moodustab paari ka ühe samast soost vanemaga.

Minu arvates sisaldab struktuur meessoost kolmikuid, kes on kahekordistatud isade ja poegadena, kolmekordset naistegelast, kahekordistatuna ema ja tütrena, ja kolmekordset kuningat, kes on paljundatud elavate kuningaks ja tema kaksikvennaks surnute kuningaks. Joonis 3 kujutab ülemises reas vanu ja alumises noori jumalaid ning toob välja nendevahelised seosed. Naisjumalate paigutus on vastavuses kosmiliste tasandite järjestusega: taevas $(\mathrm{m})$, atmosfäär $(m)$, maa (n) ja allilm (m), seda teemat olen puudutanud mujal (Lyle 1982).

\begin{tabular}{|l|c|c|c|c|c|}
\hline Jumal 1 & Jumal 2 & Jumalanna & Jumal 3 & & \\
\hline Jumal 1 & Jumal 2 & Jumalanna & Jumal 3 & $\begin{array}{c}\text { Elusate } \\
\text { Kuningas }\end{array}$ & $\begin{array}{c}\text { Surnute } \\
\text { Kuningas }\end{array}$ \\
\hline
\end{tabular}

Joonis 3 .

Teogoonia vaatlemisel on kasulik meeles pidada vahet noorte jumalate ja nende eelkäijate vahel, mis siin joonisel on välja toodud eraldi ridadesse paigutamise abil, kuid on veel üks teine eristus, mida tuleb teha seoses vaenulike kaksikutega, ja see jaotab jumalad teistsugusel viisil. Pimedusekuningast kaksik on sündinud esi- 
mesena ja näib, et valgus tekkis alles siis, kui ta vendoli sündinud nagu Ohrmazdi loos (Zaehner 1955: 56). Kõik muud noored jumalad peale pimedusekaksiku on ühenduses valgusega ja võiks tähele panna, et mõnikord on Ashvini kaksikuid kujutatud tähtedena (Ward 1968: 15-18), kuigi tegu on piisavalt keerulise juhtumiga, mida peaks eraldi uurima. Kui me ajutiselt vaatleme noori jumalaid valgusejumalatena (välja arvatud pimedusekaksik), siis on pimedusekaksik valguse puudumise tõttu seotud jumalate vanema põlvkonnaga, kuhu kuulusid kosmilised jumalad. Asjaolu, et pimedusekaksik sünnib kaksikutest esimesena, seab tema valitsemise ühendusse vanemate jumalatega, andes tasakaalus olevad rühmad: a) vanemad jumalad pimedusekuninga võimu all ja b) nooremad jumalad valgusekuninga valitseda. See pimedusekuninga kahetähenduslik positsioon on näidatud joonisel 4:

\begin{tabular}{|l|l|l|l|l|l|}
\hline Jumal 1 & Jumal 2 & Jumalanna & Jumal 3 & \multicolumn{2}{|l|}{} \\
\hline Jumal 1 & Jumal 2 & Jumalanna & Jumal 3 & Kuningas & Kuningas \\
\hline
\end{tabular}

Joonis 4.

Viiest noorest jumalikust vennast ja ühest jumalannast koosnevat rühma on võimalik märgata ka inimlikus kontekstis väljendatuna India eeposes Mahabharata,${ }^{27}$ kuid see on jällegi küsimus, mida peaks siin puudutatust pikemalt arutama. Ma siiski viitan ühele india loole müütilise kuuest lapsest koosneva rühma kohta, mis on pärit Markandeya Puranast (O'Flaherty 1975: 65-70). Vivasvati naisel Samjnal oli viis poega (Manu, Jama, Ashvini kaksikud, Revanta) ja tütar Jami ning on selge, et Ashvinite paar eristub Manu ja Jama paarist. Ashvini kaksikud tuleks niisiis paigutada etteantud noorte jumalate jadasse - mitte kuningate kohtadele, vaid kahte muusse meessoost positsiooni, arvatavasti ülalviidatud teise ja kolmanda funktsiooni alusel. Selline paigutus annab järgmise rea:

\begin{tabular}{|c|c|c|c|c|c|}
\hline Revanta & $\begin{array}{c}\text { Ashvin } \\
\text { (hobuse- } \\
\text { mees) }\end{array}$ & Jami & $\begin{array}{c}\text { Ashvin } \\
(\text { karja- } \\
\text { kasvataja) }\end{array}$ & Manu & Jama \\
\hline
\end{tabular}

Joonis 5 . 
Rooma pakub mu arvates samuti teogoonia näite, mis tipneb kaksikute sünniga. G. Dumezil näitab, et roomlased muutsid müüdid oma pseudo-ajalooks (Littleton 1982: 11-12), kuid ta võtab vaatluse alla Romuluse ja Remuse aja ja sellest hilisema perioodi ega tuvasta nende sünnile eelnenud lugu kosmogoonilise müüdina, kus jumalad on asendatud surelikega. Jutustus (Livius 1.3.10-1.4.3; Liber de viris illustribus urbis Romae 1.1-1.2) saab alguse Alba kuningas Procast, kes on Uranose kohal (meesjumal 1). Surres jätab ta maha pojad Numitori ja Amuliuse, ${ }^{28}$ Amulius on Chronose rollis (meesjumal 2). Amulius kõrvaldab võimult oma venna ja saab ainuvalitsejaks. Ta esineb ka takistajana, kui sunnib Vesta neitsiks ${ }^{29}$ hakkama Numitori tütart Rea Silviat, ${ }^{30}$ et tal ei tuleks järeltulijaid. Sellest hoolimata jääb Rea Silvia Marsist ${ }^{31}$ rasedaks ja sünnitab pojad Romuluse ja Remuse. Siin uurimuses käsitlen Marsi vahelesegajana, kes taastab jumaliku elemendi, mis läks kaduma, kui kosmiline müüt taandati surelikele tegelastele. Mars on seega kuuendalt jooniselt välja jäetud. Kaksikutel ei olnud õdesid ega vendi, kuid neid endid ja nende eelkäijaid võib näha järgmisel skeemil:

\begin{tabular}{|l|l|c|l|l|l|}
\hline Proca & Amulius & $\begin{array}{c}\text { Rea } \\
\text { Silvia }\end{array}$ & Numitor & \multicolumn{2}{|c|}{} \\
\hline & & & & Romulus & Remus \\
\hline
\end{tabular}

Joonis 6 .

Vaenulike kaksikute lugude põhjal on võimalik välja tuua indoeuroopa ja muu maailma pärimuse ühine binaarne põhi. See motiiv on hästi tuntud, kuid paradoksaalselt pole seda põhjalikumalt uuritud just seetõttu, et ta oli nii laialt levinud ega sobinud valitseva seisukohaga, mille järgi süsteemi tuli uurida eraldi ühe kindla kultuuri raames. Loomulikult on palju asju, mida on võimalik mõista ainult ühe kindla kultuuri tingimustes, kuid näib, et kuninglike kaksikute ja nendega seotud teogoonilise struktuuri motiivi ei saa piiritleda kummagi siin vaadeldud kontekstiga - ei indo-euroopa ega egiptuse omaga. Sellel paistab olevat laiem põhi.

Loo baas võib tõepoolest avarduda üle terve arhailise maailma (vt Lyle 1984b). Tekib küsimus, kas ida ja lääne arhailised religioossed süsteemid on tõesti nii eraldiseisvad, et neid ei saa tulusalt koos uurida nüüd, kui on märke selle kohta, et lääne keeruline kosmoloogiline struktuur on potentsiaalselt võrreldav hiina omaga. 
Selles artiklis käsitletud jumalad on olnud elavad antropomorfsed tegelased või isegi surelikud inimesed, kes tegutsevad pigem füüsilisel kui üleloomulikul tasandil. Kirjutise eesmärk oli kindlaks teha neid omavahel siduv ja defineeriv struktuur. Hiina puhul on väljaspool kahtlust võimsa struktuuri olemasolu. Kui seda oleks võimalik võrrelda siin käsitletud religioosse traditsiooniga, nagu mulle tundub, siis on ülesandeks taaselustada tagasivaatavalt jumalad, kes kunagi kujundasid selle struktuuri. Onnekombel on hiljuti hakanud tekkitama elevus Kwang-chih Changi ergutusel kümnest elemendist koosnev struktureeritud jada, mis võiks pealtnäha kõige rohkem vastata teogooniate kümnele jumalale, kellest oli juttu ülalpool. See on t'ien kani või "taevaste võrsete" rida, mis kujutas endast Shangi dünastia ajal (rohkem kui 1100 a eKr) kümnepäevase nädala päevade nimesid ja ka surnutele omistatud nimesid (Chang 1978; 1980: 165-89; Chao 1982: 11-19). Hilisemad allikad viitavad, et pool reast on yang (valgus) ja teine pool yin (pimedus) ning päevade nimedes on yang ja yin vaheldumisi, nii et tekib paaridest koosnev seeria: Chia ja I, Ping ja Ting, Wu ja Chi, Keng ja Hsin, Jen ja Kuei. Neljandast sajandist eKr pärit viieelemendise süsteemi iga element (Needham 1969: 232) sisaldab ühte neist paaridest ja, vaadeldes elementide suhet üksteisega kui nelja veerandit ja keskpunkti, on paar Wu-Chi keskses positsioonis (Needham 1969: 262; de Saussure 1909: 10-11).

Pannes tähele, et a) paarid on järgnevuses, b) iga paar koosneb valgest ja pimedast liikmest ja c) üks paar eristub teistest keskse koha tõttu, saab seda rida seosesse viia struktuuriga, mis on näidatud joonisel 4. Kuna kõik need tingimused on täidetud (ehkki bja c on hilisemad tundemärgid kui a), saab võrdluseks moodustada järgmise skeemi:

\begin{tabular}{|c|c|c|c|c|c|}
\hline I & Ting & Hsin & Kuei & \multicolumn{2}{|l|}{} \\
\hline Chia & Ping & Keng & Jen & Wu & Chi \\
\hline
\end{tabular}

Joonis 7 .

Changi uuringute järeldustes on mõned viited selle kohta, et siinne võrdlus võib olla tehtud õiges suunas. Ta leidis valitsejaile pärast surma omistatud kanide nimesid uurides, et nimede Chia ja I (ühes jaotuses) ja Ting (teises jaotuses) esinemissagedusel on suur tähtsus. 
See oleks vastavuses mudeliga, kus need nimed on paigutatud hierarhiliselt ülemate esimese ja teise funktsiooni asukohtadele. Ka Kengi ja Hsini positsioon on haruldaselt ebatavaline, mis võib neid liita kas Chia ja I või Tingi jaotusega. Samasugune asend on naisel, kelle kohta leidsime, et ta hoiab tasakaalu ega ole ainuliselt seotud ühegagi funktsioonidest.

Teogooniates kohatud binaarsed jadad on muidugi ahelana täiesti tuntud ka Hiinas: 1 (ülim olemus või algpõhjus) $>2$ (taevas ja maa või kaks olekut) $>4$ (neli aastaaega või sümbolit) $>8$ (kaheksa kolmikmärki) (Fung 1952-3: 2.102; I Ching, ${ }^{32}$ toimetanud Chai ja Chai 1969: xliii). Kui saaks võimalikuks ühe süsteemi terminite sidumine teise omadega, ei oleks erinevused kahe käsitluse vahel enam takistuseks, vaid nad muutuksid väga väärtuslikuks, näidates sama süsteemi kahest erinevast aspektist.

Vaenulike kaksikute sünniga tipnev teogoonia saab olla asjakohane ainult ühiskonnas, mille valitsejaks on kuningas, ja see toetab kuningavõimu ideoloogiat. Toetust ei saa pidada aga absoluutseks, mida ta oleks olnud, kui panteon oleks kulmineerunud ühe ja ainukese kuninga sünniga, sest kaksikvendlus viitab individuaalse võimu piiratusele. Aastaraamatus Cosmos ilmuvas artiklis võtan vaatluse alla kuningavõimu duaalse olemuse ühiskonnas, kus on käibel teogooniline müüt võtmekohtadel olevatest kaksikvendadest-kuningatest. Nagu Roy Williams hiljuti märkis, on binaarse sisuga süsteemid ülitavalised ja duaalsus võib olla põhjendatud inimaju ülesehitusega ning erilist seletust tuleb otsida hoopis "sisulise binaarsuse allakäigule" õhtumaises kultuuris (Willis 1985: 209-211). Võib-olla on allakäik süüdi ka selles, et mütoloogiauurimused pole seni suutnud leida viiteid binaarsele struktuurile õhtumaises teogoonias ega omistanud piisavat tähelepanu hämara kaksiku olemasolule.

\section{Tõlkinud Elge ja Elsa Leitan, Neeme Näripä}

Tõlgitud väljaandest Cosmos: Duality 1 . The Yearbook of the Traditional Cosmology Society. Edinburgh 1985, lk 1-14.

\section{Kommentaarid}

${ }^{1}$ Ashvinau. Hobusemehed, jumalikud kaksikvennad, päikese pojad, jumalate ravitsejad (tõlk).

${ }^{2}$ Kreeka traditsiooni käsitleb West 1975. 
${ }^{3}$ Apollodoros (u 180-119 eKr), pärit Ateenast. Siin mainitud ja Apollodorosele omistatud mütograafide käsiraamat "Bibliotheke" on võltsing, mis pärineb arvatavasti 2. sajandist $\mathrm{pKr}$ (tõlk).

${ }^{4}$ Soome Piibliseltsi välja antud eestikeelsest Piiblist, Finnish Bible Society 1991 (tõlk).

${ }^{5}$ Zervanism oli Pärsiast pärit religioon, mis sisaldab dualismi elemente, kuid võtab tänu Zurvanile (Zervanile) asja monoteistlikult kokku. Hellenistlikus maailmas tunti Zervanit Aionina (samastati Chronose või Saturnusega). Zervanism mõjutas gnostikute maailmapilti (tõlk).

${ }^{6}$ Vaata Zaehner 1955: 54-79, 419-428. Täieliku loo, mille pani kirja Eznik Kolbist “De Deo's", võib leida armeenia originaali prantsuskeelse tõlkega Louis Maries' ja Ch. Mercier' editsioonis (1959). Watts (1969: 129-30) annab tõlke inglise keelde prantsuse keele vahendusel.

${ }^{7}$ Titus Livius elas 59 eKr kuni 17 pKr, seega Augustuse ajal. Kirjutas roomlasile nende ajaloo "Ab urbe condita" (Rooma linna asutamisest). Teos toetas valitsevat ideoloogiat ja sisaldab ajaloolisi ebatäpsusi. Livius lähenes materjalile loovalt (tõlk).

${ }^{8}$ Tõlgitud originaalist: Titus Livius, Ab urbe condita (1.6.4-1.7.2) (tõlk).

${ }^{9}$ Jama oli Indias surmajumal, "pidurdaja". Oli alguses lihtsalt surnute kuningas, pärast muutus hirmsaks jumalaks, kes karistab inimesi nende pattude eest (tõlk).

${ }^{10}$ Manu roll on india mütoloogias sarnane Noa omale Piiblis. Müüdi järgi hoiatas kala (kes olnud Brahma või Vishnu kehastuseks) Manut suure üleujutuse eest ja käskis tal laeva ehitada. Kui Manu laevaga üksi lainetel hulpis, palvetas ta jumalate poole, kes andsid talle naise ja Manust sai inimsoo esiisa.

${ }^{11}$ Johannes Malalas (490-570 pKr) sündis ja elas Antiookias, lõi Bütsantsi kroonikate tüübi, kirjutas rahvapärases kreeka keeles (tõlk).

${ }^{12}$ Püütia oli antiikajal väga kuulus oraakel. Püütiaks oli Apolloni preestritar Delphis (tõlk).

${ }^{13}$ Malalas, Bonn, lk 171-172. Ma olen väga tänulik dr R. C. Mccaile selle tõlke valmistamise eest. Nii palju, kui ma tean, on antud lõiku Rooma kaksikute käsitlemisel harva kasutatud. Dagron küll viitab tollele oma arutluses Bütsantsi tsirkuse kohta (1974: 338-344), kuid arvab Romuluse ja Remuse ning Castori ja Polluxi võrdväärseiks kaksikuiks ning näeb üldse vähemkeerulist dualistlikku süsteemi tsirkuse sümboolikas kui mina (Lyle 1984a).

${ }^{14}$ Seth oli loomakujuline kõrbejumal, kes kehastas alguses koos Horosega vaarao valitsejavõimu. Osirise müüdis tapab ta Osirise ja on kurjade 
jõudude kehastus. Sethi võitlus Horosega on egiptuse mütoloogia peateema. Kreekas samastati teda Typhoniga (tõlk).

${ }^{15}$ Plutarchos (u $46 \mathrm{pKr}$ - pärast 119. aastat) sündis Chaironeias, reisis palju Roomas, Egiptuses. Peamised teosed "Paralleelsed elulood" ja "Moralia". Tema kirjutis Isise ja Osirise kultusest on oluline Egiptuse mütoloogia allikas (tõlk).

${ }^{16}$ Horos oli pistrikuna kujutatud egiptuse taeva- ja päikesejumal. Osirise müüdis Isise ja Osirise poeg, kes maksab kätte Sethile oma isa surma eest, kurjuse vastu võitleja. Kreekas samastati teda Apolloniga (tõlk).

${ }^{17}$ Hesiodos elas u 7. saj eKr. Tema peamised teosed on "Theogonia" ("Jumalate põlvnemine") ja didaktiline poeem "Tööd ja päevad". Mõlemad on kirjutatud heksameetris. On esimene Euroopa luuletaja, kelle kohta on säilinud isikuloolisi andmeid (tõlk).

${ }^{18}$ Üheksast jumalast koosnev rühm Egiptuses (tõlk).

${ }^{19}$ Heliopolises samastati Atumit Re'ga. Tema üheks ilmumisvormiks peeti skarabeust. Müüdi järgi sünnitas Atum Shu ja Tefnuti kas masturbeerimise või sülitamise abil (tõlk).

${ }^{20}$ Nut oli egiptuse taevajumalanna. Teda kujutatakse harilikult suure palja tagasi kummarduva naisena, keda toetab Shu. Nii moodustavad nad taeva. Nut neelas igal õhtul suu kaudu alla päikese ja hommikul sünnitas ta üsast (tõlk).

${ }^{21} 183$ ja 389 märkus 13; vaata ka Griffiths 1959: 40, 55.

${ }^{22}$ Viie noore jumala (siin artiklis peamiselt kõne all oleva kuue asemel) esinemine võib olla seotud kalendri vajadustega, milles oli 12 kolmekümnepäevast kuud, mis annavad kokku 360 päeva ja jätavad 3651/4 päevaga päikeseaastas üle viis täispäeva (vt Lyle 1986).

${ }^{23}$ Helios oli kreeklaste päikesejumal. Tema vanemateks olid titaanid Hyperion ja Theia. Helios sõitis iga päev oma päikesehobuste nelikrakendiga üle taevavõlvi läände ning naasis öösel Okeanose kaudu tagasi itta (tõlk).

${ }^{24}$ Zeusi ja Maia poeg. Hermes oli karjajumal, teekäijate kaitsja, kaupmeeste jumal ja varaste jumal ning veel palju muud (tõlk).

${ }^{25}$ Rhea oli Uranose ja Gaia tütar, Chronose õde ja naine. Teda on samastatud Väike-Aasia Kybelega (tõlk).

${ }^{26}$ Madavi - tegelane tamili eeposest "Shilappadiharam", mis on kirjutatud arvatavasti 7. sajandil (tõlk).

${ }^{27}$ Mahabharata on India suurim eepos, kirjutet eepilises sanskritis. Autoriks peetakse Vjasat. Praegune kuju pärineb arvatavasti 3. saj eKr - 3. saj pKr (tõlk). 
${ }^{28}$ Amulius oli müütiline Alba kuningas, kes kõrvaldas võimult oma venna Numitori ja mõrvas tema pojad. Amuliuse tapsid hiljem Rea Silvia pojad Romulus ja Remus. Numitor saab pärast seda jälle kuningaks (tõlk).

${ }^{29}$ Pärast Romuluse ja Remuse sünnitamist käskis Amulius Rea Silvia vanglasse panna või Tiberisse heita, kus temast sai jõejumala abikaasa. Vanema pärimuse kohaselt peeti Rea Silviat rooma näidissangari Aenease tütreks (tõlk).

${ }^{30}$ Kodukoldejumalanna Vesta preestritarid Vesta neitsid ehk vestaalid pidid valvama Vesta templis igavest tuld ja seal 30 aastat teenima. Tsölibaadinõude vastu patustamise eest karistati neid elusalt matmisega.

${ }^{31}$ Rooma sõjajumal. Kreeka vaste on Ares (tõlk).

${ }^{32}$ Eesti keeles Muutuste raamat, Buddhakirjastus 1995 (tõlk).

\section{Kirjandus}

Cameron, Alan 1976. Circus Factions: Blues and Greens at Rome and Byzantium. Oxford: Clarendon Press.

Chai, Ch'u \& W. Chai (toim), J. Legge (tõlk) 1969. I Ching . New York: University Books Inc., Bantam Paperbacks.

Chang, Kwang-chih 1978. T'ien kan: a key to thc history of the Shang. Roy, David T. \& Tsien, Tsuen-hsuin (toim). Ancient China: Studies in Early Civilization. Hong Kong: Chinesc University Press, lk 13-42.

Chang, Kwang-chih 1980. Shang Civilization. New Haven \& London: Yale University Press.

Chao, Lin 1982. The Socio-Political Systems of the Shang Dynasty. Nankang $\&$ Taipei.Taiwan: Institute of the Three Principles of the People, Academia Sinica. Monograph Series 3.

Dagron, Gilbert 1974. Naissance d'une capitale: Constantinople et ses institutions de 330 a 451. Paris.

Dumezil, Georges 1970. Archaic Roman Religion. Chicago \& London: University of Chicago Press.

Dumezil, Georges 1973. The Destiny of a King. Chicago \& London: University of Chicago Press.

Dumezil, Georges 1977. Les dieux souvcrains des Indo-Europeens. Paris: Gallimard.

Eznik of Kolb 1959. De Deo. Maries, Louis \& Mercier, Ch. Paris: Patrologia Orientalis XXVIII, 3-4.

Frame, Douglas 1978. The Myth of Return in Early Greek Epic. New Haven $\&$ London: Yale University Press. 
Frankfort, Henri 1948. Kingship and the Gods. Chicago: University of Chicago Press.

Fung, Yu-lan 1952-1953. A History of Chinesc Philosophy. Princeton: Princeton University Press.

Ginzberg, Louis 1909-1938. The Legends of the Jews. Philadelphia: Jewish Publication Society of America.

Griffiths, J. Gwyn 1959. Some Remarks on the Enneads of Gods. Orientalia n. s. 28 , lk 34-56.

Griffiths, J. Gwyn 1960. The Conflict of Horus and Seth. Liverpool: Liverpool University Press.

Griffiths, J. Gwyn (toim) 1970. Plutarch's "De Iside et Osiride". Cardiff: University of Wales Press.

Leach, Maria \& Fried, Jerome 1950. Funk \& Wagnalls Standard Dictionary of Folklore, Mythology and Legend. New York: Funk \& Wagnalls Company. Lincoln, Bruce 1975. The Indo-European Myth of Creation. History of Religions 15, lk 121-45.

Littleton, C. Scott 1982 . The New Comparative Mythology: an anthropological assessment of the theories of Georges Dumezil. Berkeley \& Los Angeles \& London: University of California Press.

Livy, (viitab) B. O. Foster 1919. Livy I-II. London \& New York: William Heinemann.

Lyle, Emily 1982. Dumezil's Three Functions and Indo-European Cosmic Structure. History of Religions 22, lk 25-44.

Lyle, Emily 1984a. The Circus as Cosmos. Latomus 43, lk 827-841.

Lyle, Emily 1984b. Distinctive Features in Cosmic Structure. Shadow l, lk 22-28.

Lyle, Emily 1986. Archaic Calendar Structure Approached Through the Principle of Isomorphism. Semiotica 61.

Lyle, Emily 1986. Whites and Reds: The Roman Circus and Alternate Succession. Cosmos 2.

Maialas, John 1831. Chronographia. Dindorf, Ludovic (toim). Bonn: Weber, Corpus Scriptorum Historiae Byzantinae.

Mercer, Samuel A. B. 1952. The Pyramid Texts. New York \& London \& Toronto: Longmans, Green and Co.

Needham, Joseph 1969. Science and Civilisation in China II. History of Scientific Thought. Cambridge: Cambridge University Press.

O'Flaherty, Wendy Doniger 1975. Hindu Myths. Harmondsworth: Penguin. 
Puhvel, Jaan 1975. Remus et frater. History of Religions 15, lk 146-57.

Saussure, Leopold de 1909. Les Origines de l'Astronomie Chinoise. Leiden: Brill.

Trevarthen, Colwyn 1984. Dual Experience with a Two-Part Brain. Shadow l, lk 17-21.

te Velde, H. 1967. Seth, God of Confusion. Leiden: Brill.

Ward, Donald 1968. The Divine Twins: An Indo-European Myth in Germanic Tradition. Berkeley \& Los Angeles: University of California Press.

Watts, Alan W. 1969. The Two Hands of God: The Myths of Polarity. New York: Collier Books.

West, M. L. 1975. Immortal Helen: An Inaugural Lecture. London: Bedford College, University of London.

Willis, Roy 1985. Do the Fipa have a word for it? The Anthropology of Evil. Parkin, David (toim). Oxford: Basil Blackwell, lk 209-223.

Zaehner, R. C. 1955. Zurvan: A Zoroastrian Dilemma. Oxford: Clarendon Press. 